Portland State University

PDXScholar

Dissertations and Theses

Dissertations and Theses

Summer 8-19-2014

\title{
Using Music-Related Concepts to Teach High School Math
}

Vytas Nagisetty

Portland State University

Follow this and additional works at: https://pdxscholar.library.pdx.edu/open_access_etds

Part of the Educational Methods Commons, Other Music Commons, and the Science and Mathematics Education Commons

Let us know how access to this document benefits you.

\section{Recommended Citation}

Nagisetty, Vytas, "Using Music-Related Concepts to Teach High School Math" (2014). Dissertations and Theses. Paper 1958.

https://doi.org/10.15760/etd.1957

This Thesis is brought to you for free and open access. It has been accepted for inclusion in Dissertations and Theses by an authorized administrator of PDXScholar. Please contact us if we can make this document more accessible: pdxscholar@pdx.edu. 
Using Music-Related Concepts to Teach High School Math

by
Vytas Nagisetty

A thesis submitted in partial fulfillment of the requirements for the degree of

Master of Science in Teaching

in

General Science

Thesis Committee:

William Becker, Chair

Cary Sneider

Melissa Potter

Portland State University

2014 


\begin{abstract}
The purpose of this research was to test a strategy which uses music-related concepts to teach math. A quasi-experimental study of two high school remedial geometry sections was conducted during a review lesson of ratio, proportion, and cross multiplication. A pretest was given to both groups. Then, Group A received normal textbook instruction while Group B received the treatment, Get the Math in Music, which is an online activity involving proportional reasoning in a music-related context. Afterwards, a posttest was given to both groups. Pretest and posttest scores were used to compare gains in subject knowledge between the groups. Then a second evaluation of the treatment was conducted. Group A received the treatment and took a post-posttest. Score gains for Group A before and after receiving the treatment were compared. After these tests, all participants took a survey to determine if their appreciation of math grew as a result of the treatment. Finally, interviews were conducted to provide better understanding of the results. The research questions of this study were: to what extent does the integration of Get the Math in Music improve students' academic performance in a remedial geometry review of ratio, proportion, and cross multiplication, and to what extent does participation in the Get the Math activity improve students' attitudes towards math? My hypotheses were that students would perform significantly better on a subject knowledge test after receiving the treatment, and that all students would have a more positive attitude towards math after receiving the treatment. Quantitative results did not triangulate to support or refute these hypotheses. Greater improvement from pretest to posttest was statistically correlated with Group B, which was the group first receiving the treatment. But later,
\end{abstract}


between posttest and post-posttest Group A did not show statistically significant greater gains after receiving the treatment. Surveys results showed that students did not necessarily like math any more after the treatment. Interviews revealed that several of these students were apathetic to geometry in particular, if not to math in general. The case of one student's improvement suggested that positive teacher-student relationships are more effective than any particular method to increase academic performance and student engagement. Survey results were consistent with earlier psychological studies claiming teenagers care about music. Additional studies in the future on the merits of using music to teach high school math would be useful. Claims that proportional reasoning is challenging were supported. It would be beneficial to evaluate the treatment in an Algebra or Pre-Algebra setting when students first study proportions. 


\section{Acknowledgements}

I would first like to thank my thesis advisor, Melissa Potter, for her steadfast support. Additionally thanks are due to committee members William Becker and Cary Sneider for offering their wisdom. Thank you to Stephanie Wagner for opening the door and finding a path for me to the Center for Science Education at Portland State University. Thank you to Laurie Cremona for her statistical expertise. A big thanks goes out to my cohort at the CSE. Lastly I would like to thank my family, especially my wife, Jacqueline, and baby daughter, Vivienne, for being so patient with me as I finished this goal. 


\section{Table of Contents}

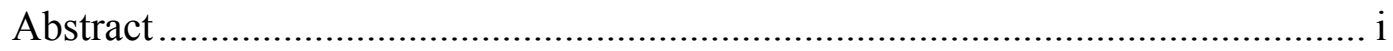

Acknowledgements ............................................................................. ii

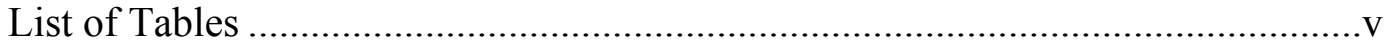

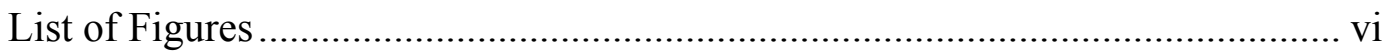

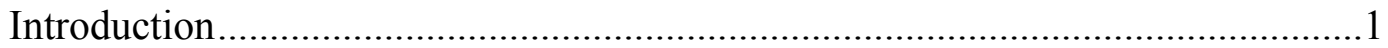

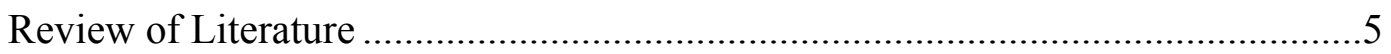

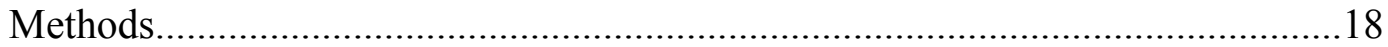

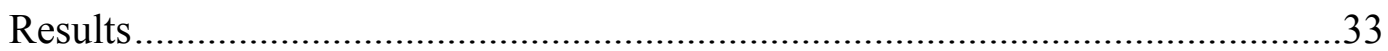

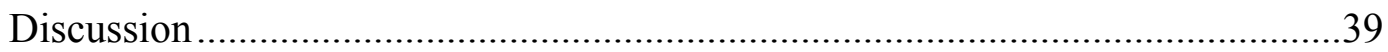

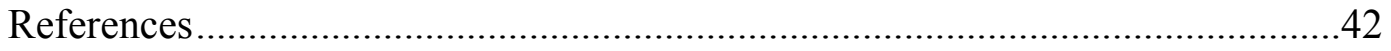

Appendices
A. Instruments.
B. Complete Quantitative Data Set......................................................51
C. Complete Interview Notes................................................................53 


\section{List of Tables}

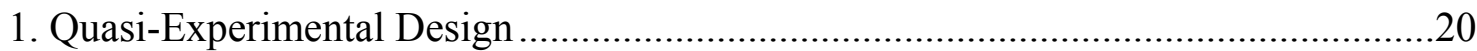

2. Comparison of pretest to posttest gains by group ................................................33

3. Comparison of pretest to posttest and posttest to post-posttest gains for Group A ....35 


\section{List of Figures}

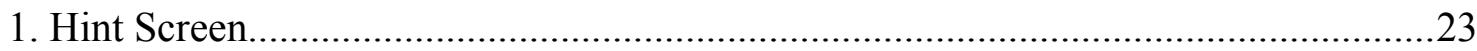

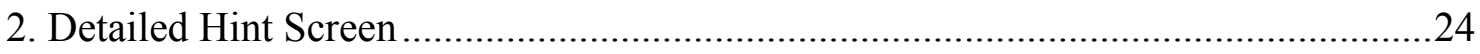

3. Pretest to posttest gains by group.............................................................. 34

4. Pretest to posttest gains and posttest to post-posttest gains for Group A compared...35 


\section{Introduction}

Mathematical reasoning is part of our daily lives. We estimate how long it will take us to get to school or work. We pay our bills. We cook our dinner. We use math in all of these activities.

At the same time, learning math is challenging for many people (National Science Foundation, n.d.). Mathematical concepts can be abstract and difficult to visualize. Consequently, math can be frustrating for students to the point where they lose interest in the subject.

One solution to make math more interesting for students is to use real world examples when teaching mathematical concepts (Ben-Chaim, Keret, and Ilany, 2007). Such examples may help students concretize abstract mathematical ideas. Also, using real world examples that specifically connect to students' experience and interests can be an effective teaching strategy (Vasquez, Sneider, and Comer, 2013). Providing such examples, and creating activities around them, motivates the students. This approach increases the students' enjoyment of learning math and consequently may improve their academic performance in the subject.

Studies have shown significant evidence that most teenagers love music (North and Hargreaves, 1999). For teens, choosing what music they like is part of the psychological formation of their identity. Music is like a badge which reflects adolescents' personalities and influences who they want to associate with. As such, music is an important part of the experiences and interests of most teenagers. 
Considering all of this, using music-related real world examples may be an ideal choice for educators when faced with the challenge of teaching adolescents mathematics. Examples from other subjects besides music may be of more interest for some individuals. But if a high school teacher wants to spark an interest in math for the majority of students, then music-related examples of math might be the most effective tool.

Various theories exist about the profound connections between math and music (Cohen, 1961), and engineering and music (Baggi, 2007). These theories help explain why studying music positively influences a learner's ability to think mathematically. Music involves rules, logic, notation, functions over time, and other concepts found in math.

Furthermore, music and math integration in the classroom has been shown to be an effective teaching strategy with other age groups (Johnson and Edelson, 2003; Wright, 2009; Courey et al., 2012; Still and Bobis, 2005). Despite this, I have not found any studies to date that investigate the potential benefits of integrating math and music in high school level coursework. This lack of existing research was part of the rationale for this study.

Of all concepts in mathematics, ratio and proportion are two of the most difficult to teach and to learn (Lamon, 2007; Vasquez, Sneider, and Comer, 2013; Ben-Chaim, Keret, and Ilany, 2007). The two concepts are typically introduced in middle school and then further developed in high school algebra. They are essential for understanding higher mathematics. For example, in geometry ratio and proportion are used when 
discussing similarity. Proportional reasoning is also important in science. For example scales and rates are based on ratio and proportion. Social scientists use scale in demographic data analysis. Physicists use rates in a multitude of ways to describe the universe and where we live. Daily tasks like cooking also require an understanding of ratio and proportion.

Considering the difficulty of teaching and learning ratio and proportion, and the age of the students when these concepts are introduced in school, using music-related real world examples might be a good strategy for instruction. The purpose of this research was to test such a strategy. I implemented a music-related activity called "Get the Math in Music" in a high school remedial geometry class. This activity served as the treatment in my study which was based on a quasi-experimental design (Trochim, 2006).

Get the Math in Music is an activity in which students use the concepts of ratio, proportion, and cross multiplication in a real world scenario involving music production. Setting up equations, such as proportions, and using them to solve problems is one of the Common Core State Standards for Algebra (National Governors Association, 2010). Therefore, the treatment aligned with the state standards.

The research questions of this study were: to what extent does the integration of Get the Math in Music improve students' academic performance during a remedial geometry review of ratio, proportion, and cross multiplication, and to what extent does participation in the Get the Math in Music activity improve students' attitudes towards math? The treatment Get the Math in Music was the independent variable. Two dependent variables were measured. One was the level of improvement in solving 
problems involving ratio, proportion, and cross multiplication. This was measured by comparing pretest and posttest scores of two non-randomized groups of students, one of which received the treatment. A second measurement was taken by comparing gains in test scores of the same group after regular instruction, and after receiving the treatment. Another dependent variable was the attitude of the students towards math. This was measured with a survey given to all students after receiving the treatment. Semistructured interviews were also used to add greater understanding of the results. In sum, my method was a mixed methods quasi-experimental design and it used both quantitative and qualitative instruments with convenience samples. My hypotheses were that all students would have significantly greater increases in test scores, and have a more positive attitude towards math, after receiving the treatment. 


\section{Literature Review}

This literature review provides evidence why this research is significant and why this treatment may actually work. It also provides a background of existing studies of a similar nature. Therefore in a broad sense, all of the literature presented here is in some way related to the teaching of ratio, proportion, and cross multiplication in a musicrelated context to high school students. Each article or chapter reviewed falls into one of four categories. First, there is literature discussing the difficulties in understanding ratio and proportion for both students and teachers. These show that the teaching of ratio and proportion is one of the most difficult challenges in math education. The second category considers the phenomenon that teens are especially interested in music as part of creating their identity. It discusses the strong connection between music and adolescence grounded in psychology. Third, there are articles which discuss the theoretical relationship between math and music. These offer explanations for the efficacy of math and music integration in education - but they do not test them. Last, there is literature which discusses the practice of math and music integration. Some authors suggest classroom techniques, while others discuss and test quantitative or qualitative outcomes. I summarize examples from each category here.

\section{Challenges Teaching Ratio and Proportion in Mathematics}

Vasquez, Sneider, and Comer (2013) describe difficulties and successful strategies for teaching ratio and proportion in middle school. A science teacher, Michael Comer, narrates the story of the challenges his $7^{\text {th }}$ grade students are having with several mathematical concepts. The students had difficulty visualizing large quantities often 
found in real world examples. Furthermore, the students' struggled to understand ratios when large numbers are involved. Proportions were even more difficult because they compare two ratios. Lastly, Comer and his fellow teachers at the middle school concurred that the students struggled to recognize the importance of math in their daily lives. To overcome these challenges, Comer and his colleagues created a multidisciplinary unit on travel which emphasized the practical applications of math using rates, ratios, proportions, and scale. For two weeks, math, science, social studies, and language arts classes focused on these concepts within their respective contexts. One motivation of such a multidisciplinary strategy is to show students that they can learn a particular concept in a variety of ways. Comer and his math counterpart also used an interdisciplinary approach emphasizing and coordinating the learning goals common to both science and math. Both teachers recognized that despite all of these efforts the students still lacked an enduring understanding of ratio and proportion that could be applied in real life situations in the future. In response, the math teacher created a transdisciplinary unit - one that would be relevant and meaningful for the students in the present. Inspired by the children's novel, The Borrowers, the class goal was to build a scale piece of furniture for either a giant or a four-inch-tall person. An investigation ensued in which the students discussed and formulated how big the body parts of a giant or a Borrower are, using their own bodies and proportion to find the answers. The students then designed the furniture with this new understanding of proportion. In conclusion, the transdisciplinary approach of tying a math concept to the personal 
interests of the students was the most effective way to impart an enduring understanding upon them.

The concepts of ratio and proportion are not just difficult for students, but for teachers as well, as illustrated by Ben-Chaim, Keret, and Ilany (2007). These concepts have been the interest of mathematicians for centuries. Despite this, proportional reasoning $(\mathrm{PR})$ is still challenging today, even for math teachers. The authors suggest that teacher training programs should include tasks involving the applications of PR which incorporate cognitive, affective, and pedagogical components. They designed and taught a course for pre-service teachers built upon those criteria. The purpose of their paper is to discuss the PR tasks they used in the course, and to report the benefits. The PR tasks the authors designed fall into one of four categories: introductory, rate, ratio, and scaling. The scaling tasks were the most difficult. These involved drawing proportional sketches of objects such as a temple or a desk, and using them to answer questions about the structures they depict. For example, the learner was asked to provide various measurements, such as perimeter and area, of the real world object based on their sketch. A vast majority of learners incorrectly identified the area relationship between their sketch and the real world object as linear instead of quadratic. Furthermore, PR questions dealing with volume were too difficult for the student teachers. The authors note that the student teachers were enthusiastic about doing the task even though many struggled with some of the questions. The benefits of the course for the learner were assessed with pretests and posttests as well as surveys. Pretest to posttest scores showed significant improvement in PR understanding for the learners: the average score 
increased from $45 \%$ to $90 \%$ correct. Additionally, attitude scores indicated an increase in enthusiasm for teaching math in general and greater confidence in teaching ratio and proportion. In conclusion, the authors found that students given PR tasks involving real world objects improved mathematical content knowledge, pedagogical-didactical knowledge, and also opinions regarding teaching and learning mathematics.

In sum, the concepts of ratio and proportion are difficult to understand for both pre-service teachers and students. Both articles emphasize the effectiveness of using real world examples when teaching these concepts. In particular, real world examples that are of personal significance to the students are the most effective to spark their interest in the concepts, to motivate them to properly use the concepts, and to improve their understanding of the concepts.

\section{The Connection Between Music and Adolescent Psychology}

North and Hargreaves (1999) report on four studies that explain how music impacts adolescents socially and psychologically. The authors begin by providing statistics about the consumption of music by adolescents and show that it is on a massive scale. According to studies by experts in sociology and communications, this consumption is due to the fact that adolescents use music as a badge of identity. Music is part of the social cognition of teens. Teens discriminate one another based on musical taste. Musical preferences influence who adolescents want to be friends with, who they want to be romantic with, and who they want to avoid. A teenager has different expectations of people based on the musical tastes of those people. The first study presented was done in the U.K. and involved distributing a questionnaire to a sample pool 
of 120 late adolescents. The questions posed regarded demographic information, personal preference of one of three musical styles (chart pop, indie pop, and classical music), and participant perceptions of the fans of each of those three styles. The results showed that the participants perceived that fans of classical music were more religious and from a higher social class compared to fans of indie pop and chart pop. That is, these older adolescents perceived they could determine demographic status of another person based on that person's musical taste. The second study was similar to the first, but involved a sample pool of early adolescents. The results of the second study also showed that early adolescents hold normative expectations regarding fans of particular musical styles. The third study also used questionnaire data obtained from middle to late adolescents. It sought to find out if these participants believed that the choice of music by a person had social consequences. The results showed that these youth believed that their own preference for a specific musical style would illicit a range of treatment by other people towards them. The overwhelming majority of participants believed their own choice of music would cause others to either respect them, or make fun of them, or think they are a leader, or want to go on a date with them, or several other possibilities. The final study used a questionnaire given to adolescents to investigate self-to-prototype matching, which is based on the assumption that individuals are motivated to reinforce their self-image. The results showed that an individual's self-esteem increased with the extent to which they identified with the fans of their preferred musical style. The authors conclude that for adolescents music does function as a badge of identity that impacts their relationships with others, their choice of friends, and their own self-esteem. 
From this article we see that psychological research has found evidence suggesting that adolescents are deeply connected to music. For teenagers music plays a vital role in their identity, self-esteem, and connection to peers. Thus for high school students, music is of a personal interest - perhaps more so than with any other age group.

\section{Music and Math Integration Theory}

Articles discussing the theory of integrating math and music often trace its historical path. Cohen (1961) shows that the concept of math and music as complimentary disciplines is not new. The Pythagorean school of Greek antiquity founded a fourfold path to knowledge called the quadrivium. It consisted of arithmetic, geometry, music, and astrology. Math and music remained grouped in Western education until the Renaissance. Cohen points out three aspects in which math and music are similar. First, they are similar because they are systems of symbols that do not necessarily point to anything - only to themselves, their antecedents, and their successors. In other words, math and music are self-referential. Second, the creative process in doing math and in doing music involves selecting from a multitude of possibilities. This choice is driven by aesthetics and a desire for elegance in both disciplines. For example, a concise, well-proportioned proof can be compared to a musical masterpiece. Lastly, both music and math are created by building from a set of predetermined presumptions, or axioms. In this endeavor order is important - each new statement is connected to the preceding with a system of logic. The arrangement of the statements in time is important. In conclusion, the enjoyment of doing math is related to the same kind of satisfaction one may have when composing or performing music. 
By extension, music integration is also useful in other math-related disciplines like engineering. Music exemplifies both structure and aesthetics important to engineers. According to Baggi (2007) the disciplines of music and musicology produce skills which positively impact creative engineering because they pose similar problems. The study of music involves the search and identification of structures, as well as developing a sense of intuition and aesthetics. Such skills are important to engineers tasked with creating easy-to-use products - a demand of the modern market. The author presents a hierarchy of engineering solutions in a chain of command structure ascending as follows: mechanical, electrical, software, artificial intelligence, and art/music. Each piece builds upon the previous. The art/music layer is the aesthetic and intuitive component of engineering design. Another reason why the study of music is beneficial for engineers is because the practice of music illustrates how working on one problem may help find the solution for another. For example, studying a Joplin rag may improve a pianist's ability to play a piece by Chopin. The view of a given problem - how to play the piano - using different representations gives a better understanding of its real nature. The author also points out that the strong dichotomy between art and science is relatively new. He lists musical skills which involve computational thinking such as the realization of unfigured bass, the improvised substitution of chords, and the construction of an improvised melody. These skills require not only understanding of algorithm and recursion, but also of aesthetics. Baggi concludes that for these reasons, engineering education would only benefit from inclusion of music and musicology into its curriculum. 
These articles show us that music, math, and engineering have a lot in common. All demand an understanding of rules, logic, and aesthetics. Math and music involve notation and symbolism. If we as educators find that many people don't enjoy math but they do like music, we may offer ways to improve their appreciation of math by pointing out its similarities to music, and by integrating music-related concepts into mathematical study.

\section{Music and Math Integration Practice}

The literature addressing the actual practice of music and math integration includes example exercises for the classroom. Johnson and Edelson (2003) present several activities to integrate music and math. Each activity is designed to target a particular grade band within elementary school. The overall goal is to help children gain access to math through new intelligences. The authors remark that language, music, art, and mathematics are "multiple sign systems" (p. 474) that increase our ability to express what we know in multiple ways. The first activities they present teach children (grades pre-K through 3) to create, perform, analyze, and graph patterns with numbers and names. In the following activities they explore various other topics including: the concept of serial order with musical pitches played on a keyboard, sorting of instruments, problem solving involving instrument combinations, illustrating instrument groups with Venn diagrams, expressing ratios sonically with instrument groups, and learning ratios on related musical instruments through measurement. The authors conclude that they hope the activities presented will help students learn math in challenging and enjoyable ways. 
While primary school integration has a focus on musical performance, at the university level, musical theory is more applicable to the level of math studied. In his college textbook David Wright (2009) covers diatonic and chromatic scales, intervals, rhythm, meter, form, melody, chords, progressions, equal and mean tone temperament, just intonation, overtones, timbre, and formants. All of which deal with musical theory. The mathematical concepts covered include integers, rational and real numbers, equivalence relations, geometric transformations, logarithms, sequences and series, groups, rings, modular arithmetic, periodic functions, and numerical integration. The physics of sound is also discussed. The ways in which music and math are intertwined are seemingly endless.

The practice of integrating music and math in the classroom has also been tested quantitatively. According to Courey et al. (2012), the integration of academic music with mathematics instruction - specifically for teaching the concept of fractions to thirdgraders - can have a positive impact on learning. Their study examined the effects of an academic music intervention on conceptual understanding of music notation, fraction symbols, fraction size, and equivalency. The link between music and math in this application is that they both offer a semiotic means of objectification, one physical, the other abstract. Music instruction involving clapping rhythms functioned as a semiotic game grounded in Vygotsky's concept of a zone of proximal development. It allowed students to make meaning of fractions in a concrete way. The gesture of clapping a rhythm served as a physical symbol whose counterpart in the abstract can be represented by a mathematical fraction. Thus the students learned the concept of fractions with a 
concrete model before tackling it in the abstract. The authors found that students in the experimental group (who received music instruction with math) outperformed students in the comparison group (who only receive math instruction) in posttests involving fractions. Moreover they found the gains to be greater from pretest to posttest by the experimental group. The authors conclude that integration of music and mathematics can be beneficial to the students' learning, and that finding other connections between the two disciplines in the classroom may both improve students' math performance and save music instruction in our schools.

In addition to quantitative studies, a fair amount of the literature documents qualitative studies. Still and Bobis (2005) present a case study of a primary school teacher who integrates math and music in his classroom. The authors wanted to find out why some teachers utilize integration as a strategy. Their case study involves interviews, observations, and documentation collected over a three week period, and focuses on one third-grade class in Sydney, Australia. The teacher had a musical background and an appreciation for math. The collected research data was organized into four themes: a typical lesson, style of teaching, impact on students, and degrees of integration. Typical lessons brought together elements common to both math and music presented in story form. Additionally, through the course of the day the students would sing scales and songs, chant and dance while reciting multiplication tables, and play recorder in a callresponse format with the teacher. The concept of time in particular was covered during the three weeks of the case study. The style of teaching was aimed to educate the whole person by thinking, feeling, and doing to create deep learning and significance. 
Additionally the teacher's method was to give the students experiences that lead them to discover new concepts. The impact on students was positive: they were excited to solve math problems that came from the story, and they gained understanding of the importance of time in music performance, not just math. The teacher admits that, considering the age of his students, the level of integration between math and music is not particularly deep. But with the foundation established, the level of integration could occur at deeper levels as the students got older. In conclusion, the authors claim this research raises some questions about teaching math through an integrated approach. In particular: do teachers need expert knowledge in both content areas? Overall, the authors seem optimistic that integration strategies will help make the classroom more enjoyable for the students, and will improve their learning.

These articles show that math and music can be integrated in academic coursework for a wide range of age groups. Such integration has delivered positive quantitative and qualitative outcomes. What is lacking in the body of literature is research that tests a music integration strategy in a high school level math classroom. My research sought to contribute to this space and to help complete the picture of how the integration of music-related concepts in mathematical study may have positive outcomes during the entire span of academic instruction.

\section{Summary}

In conclusion, we have seen in these articles that the concepts of ratio and proportion are difficult for both students and teachers. We also have seen that adolescents in particular have a profound connection to music psychologically and 
sociologically. These circumstances were the preliminary motivation for my research. They begged the question: what would be the effect of using music-related examples to teach adolescents about ratio and proportion?

The literature shows that the concept of integrating music with math in a learning environment is not new. I found strategies in primary school connecting music performance with math. For college level students, I found the use of music theory to discuss math. However, examples in the literature of either type of integration at the high school level were not found. The efficacy of music and math integration has only been tested (quantitatively and qualitatively) at a primary school level. This testing has shown positive outcomes when music and math education are combined. Consequently, I believed there would be value in researching the least tested strategy: the integration of music-related examples with high school level math.

Ratio and proportion are reviewed in high school geometry when introducing similarity (Carter et al., 2010). The rationale of this thesis was motivated by this fact, and by four conclusions from the literature review. First, ratio and proportion are difficult for students and teachers. Second, high school students are deeply connected to music. Third, music and math are related in theory. Lastly, the existing literature lacks studies of the effect of music and math integration for high-school students. A study testing the quantitative and qualitative outcomes of teaching ratio and proportion to high school students while using music-related examples appeared to be a new contribution.

The general goal of this research was to find engaging ways to introduce high school students to the mathematical subject matter that they must learn to comply with 
national standards. I wanted to learn if music integration produces greater student engagement in math. I measured engagement as better understanding and more enjoyment of the subject. Specifically this study tested the effect of integrating a musicrelated activity (Get the Math in Music) into a remedial geometry lesson during a review of ratio and proportion. 


\section{Methods}

\section{Overview}

There were two research questions in this study. First: to what extent does the integration of the music-related math activity Get the Math in Music improve students' academic performance during a review of ratio, proportion, and cross multiplication? Second: to what extent does participation in the Get the Math Activity improve students' attitudes towards the subject of math in general? I was seeking both quantitative and qualitative answers. The general methods I used were based in part on those used in a study by Ben-Chaim, Keret, and Ilany (2007) which measured knowledge gains and attitude shifts of pre-service teachers after receiving a treatment on proportional reasoning which involved activities with real world applications.

The quantitative instruments I used consisted of a pretest, a posttest, a postposttest, and a survey. The tests used problems adapted from the McDougal Littell 2007 edition Algebra I textbook and the Get the Math in Music activity. The survey was modeled after one used in a study by An et al. (2007), which tested for gains in preservice teachers' interest in math after receiving a music integration treatment. The qualitative instrument was semi-structured interviews with questions modeled after those used in the study by Ben-Chaim, Keret, and Ilany (2007).

This quasi-experimental study (Trochim, 2006) compared the gains in academic performance and positive attitude of two groups of high school students $\left(N_{\text {comp }}=24, N_{\text {exp }}=19\right)$ during a review of ratio, proportion, and cross multiplication in a remedial geometry course. During the semester, as part of an introduction to similarity, 
both groups were presented a one lesson review of ratio, proportion, and cross multiplication. Two weeks before this review all students took a pretest. During the review, both groups discussed ratio, proportion, and cross multiplication, but with different examples. Group B worked on problems with the treatment: an online activity called "Get the Math in Music." Group A received normal instruction and worked on two problems unrelated to music: calculating the student-teacher ratio at their school, and calculating if a person had enough gas to go from Portland to Bend. At the end of the lessons, the students in both groups received a posttest to measure their improvement. To be equitable, a week after the posttest, Group A also received the treatment. Group A then took a post-posttest as another measure of the effectiveness of the treatment. After all students received the treatment both groups completed a survey asking whether the Get the Math in Music activity improved their attitude towards math. Lastly, after all tests and surveys were completed, a subset of students took part in semi-structured interviews to add insight and explanations to the results.

The treatment Get the Math in Music was the independent variable. It involved using ratio, proportion, and cross multiplication to solve music-related story problems. Two dependent variables were measured. One was the level of improvement in solving problems involving ratio, proportion, and cross multiplication. This was measured by comparing pretest to posttest scores, as well as posttest to post-posttest scores for Group A. Another dependent variable was the students' attitude towards math. It was measured by a survey questionnaire using a Likert scale for responses. The survey questions asked all students about their attitude towards math and about whether doing problems with 
music-related applications changed this attitude. Lastly, semi-structured interviews were conducted by me with a subset of the participants during the week following the lesson. These interviews focused on learning why the results of the tests and surveys were what they were. A diagram of this study is provided here in Table I:

Table 1: Quasi-Experimental Design

\begin{tabular}{|c|c|c|c|c|}
\hline & $\begin{array}{l}\text { Two } \\
\text { weeks } \\
\text { prior }\end{array}$ & Day 1 & Day 2 & $\begin{array}{l}\text { The Week } \\
\text { Following }\end{array}$ \\
\hline $\mathrm{N}_{\mathrm{a}}$ & $\mathrm{O}_{\mathrm{A}}$ & $\mathrm{O}_{\mathrm{B}}$ & $\begin{array}{l}\mathrm{X}, \mathrm{O}_{\mathrm{C}}, \\
\mathrm{O}_{\mathrm{D}}\end{array}$ & $\mathrm{O}_{\mathrm{E}}$ \\
\hline $\mathrm{N}_{\mathrm{b}}$ & $\mathrm{O}_{\mathrm{A}}$ & $\begin{array}{l}\mathrm{X}, \mathrm{O}_{\mathrm{B}}, \\
\mathrm{O}_{\mathrm{D}}\end{array}$ & & $\mathrm{O}_{\mathrm{E}}$ \\
\hline
\end{tabular}

Key: $\quad \mathrm{N}_{\mathrm{a}}=$ non-randomized study group $\mathrm{A}$

$\mathrm{N}_{\mathrm{b}}=$ non-randomized study group $\mathrm{B}$

$\mathrm{X}=$ Get the Math in Music treatment

$\mathrm{O}_{\mathrm{A}}=$ pretest

$\mathrm{O}_{\mathrm{B}}=$ posttest

$\mathrm{O}_{\mathrm{C}}=$ post-posttest

$\mathrm{O}_{\mathrm{D}}=$ survey

$\mathrm{O}_{\mathrm{E}}=$ student interviews 


\section{Participants}

This study involved two remedial geometry classes taught by two different teachers at a suburban school in Northwest Oregon. The total sample size was 43 students $(N=43)$. Each pre-selected class remained intact instead of participants being randomly assigned to one of the two groups. These groups were chosen with the consultation of the math faculty at the school. The criterion was that both groups needed to be evenly matched in academic performance and that their teachers were willing to let their classes participate in the study. These sections consisted of students who had failed Geometry during the preceding semester. The demographic of the student body at the school contained a wide range of ethnic backgrounds: 44\% White, 25\% Hispanic, 14\% Asian, 1\% Pacific Islander, 5\% of mixed race, 10\% Black, and 1\% Native American. The majority of these students were from a low socio-economic status $(74 \%$ receive free/reduced lunch) and lived in neighborhoods close to the school.

\section{Treatment}

The treatment involved taking part in a short online activity called "Get the Math in Music.” It was developed by me in 2010 for WNET, a PBS affiliate in New York City. The activity may be found via the following web link:

\section{http://www.thirteen.org/get-the-math/the-challenges/math-in-music/introduction/20/}

Get the Math in Music involved setting up proportions and using cross multiplication to solve them. The task of creating and solving proportions was done in the context of music production, where two rappers were trying to adjust the tempo of a drum track so that it would match the tempo of a particular instrumental audio sample. 
The drum track was computer generated and its tempo was set in beats per minute (BPM). By finding the BPM of the instrumental sample, the students were able to adjust the tempo of the drum track accordingly.

The Get the Math in Music activity began with a video which introduces the rappers and the problem at hand. The rappers discussed how they feel math is important in music and shared their own stories of how their love of music coincided with an appreciation of math. Then the problem of finding the BPM was posed to several students visiting the recording studio. The students in the video broke into teams of two and discuss how they would go about solving the problem.

After the introductory video, Get the Math in Music continued with a computer activity which guided the students through the problem and solution. The students were first given the duration and were asked to count the number of beats in the instrumental audio sample. Then they calculated the BPM of the instrumental sample by setting up either of the following equations and solving for BPM:

$\frac{\text { number of beats in the instrumental sample }}{\text { duration of the instrumental sample in seconds }}=\frac{\text { BPM }}{60}$

or

$\frac{\text { number of beats in the instrumental sample }}{\text { BPM }}=\frac{\text { duration of the instrumental sample in seconds }}{60}$

If the students had difficulty setting up the problem, a hint screen was provided: 
Figure 1: Hint Screen.

\section{Math in Music \\ Take the challenge}

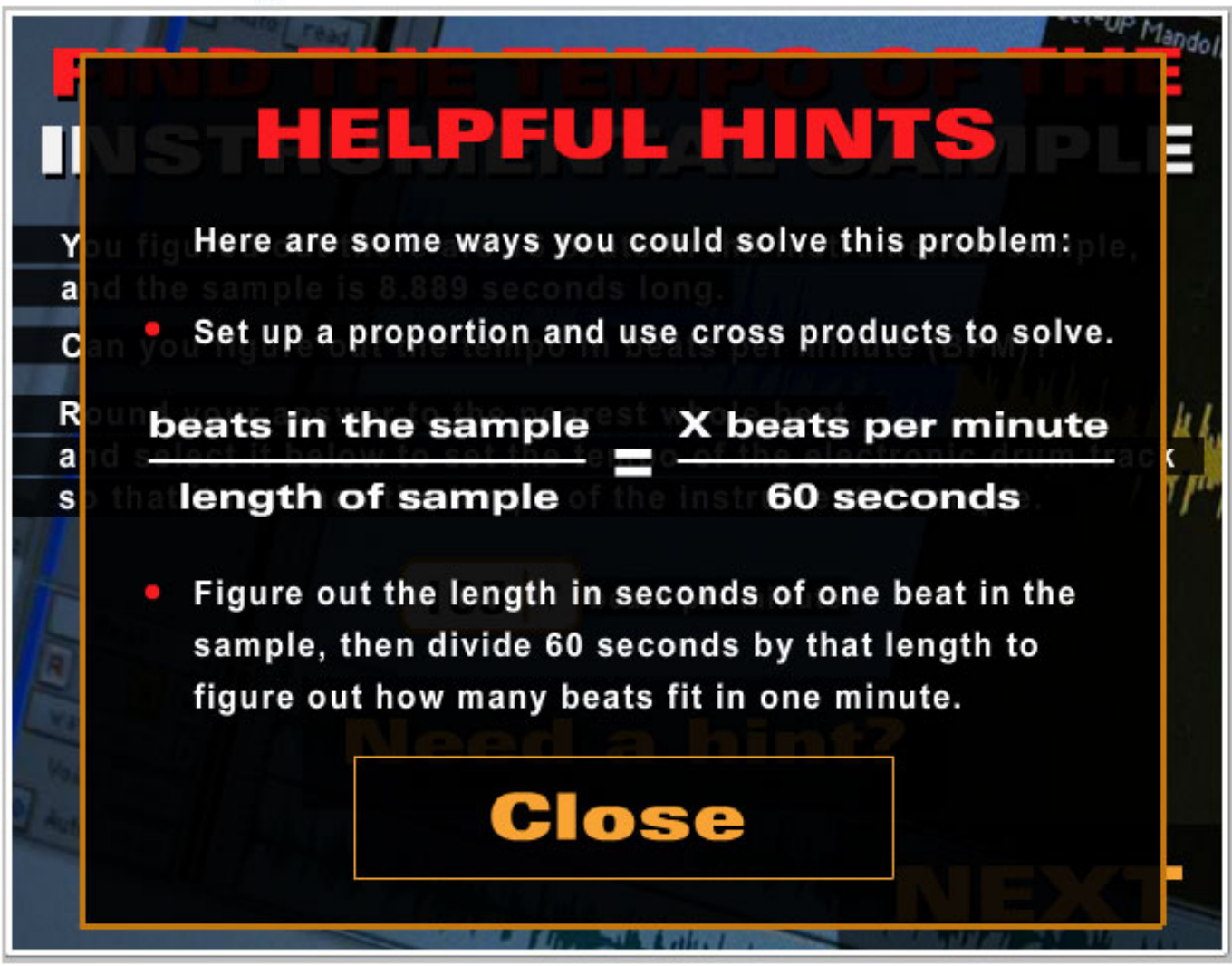

Previous: Introduction

Next: See how the teams solved the challenge

After choosing a value for BPM, a mix of the drum track and instrumental sample were played back. If the student had chosen the correct BPM, the mix sounded correct the two parts were be in synch. If they chose the incorrect BPM, the drum track sounded out of synch with the instrumental sample. Additionally, if they chose the incorrect BPM, a more detailed hint screen was provided: 
Figure 2: Detailed Hint Screen.

\section{Math in Music}

Take the challenge

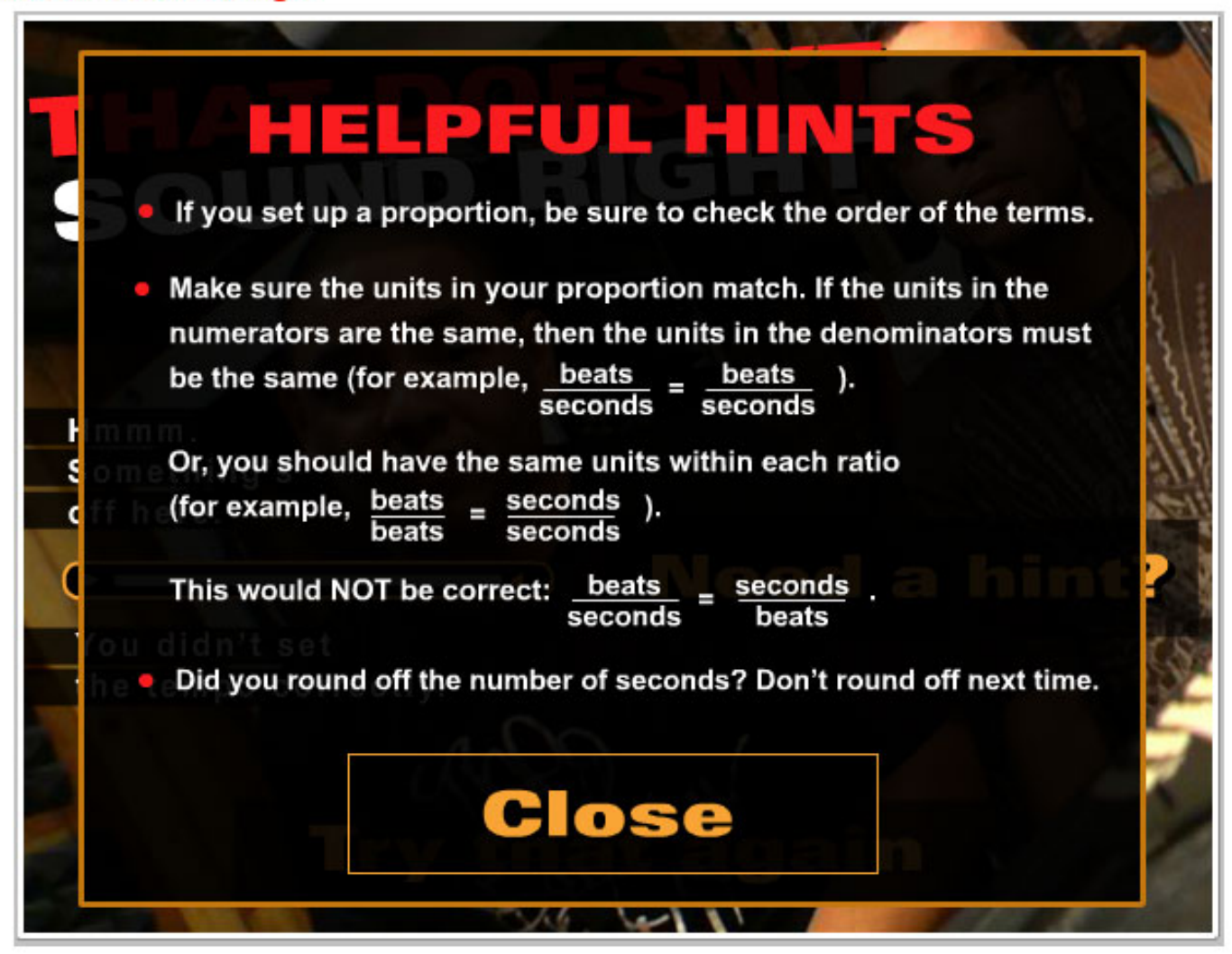

Previous: Introduction

Next: See how the teams solved the challenge

Once the students had completed this task successfully, they were given a second challenge of the same design but with the opportunity to choose from several different drum tracks and instrumental samples. The students in both groups completed the entire activity in approximately 40 minutes. 
Group A took part in normal class instruction taught by me. The lesson involved solving two problems. First, given how many teachers and students there are at this high school, what is the student-teacher ratio? Second, a person wants to drive to Bend from Portland. Their gas tank holds 12 gallons and is $3 / 4$ full. Their car gets 20 miles per gallon. The route is 150 miles via US 26, and 185 miles via OR22. Does the person have enough gas to get there? Why? By which route? What fraction of a tank should it read on the fuel gauge for each route? Students offered answers with explanations to these questions. The concepts of ratio, proportion, and cross multiplication were reviewed.

Both groups received instruction that involved math problems based on real world applications. The major difference was that the group receiving the treatment solved these problems in the context of music production while the group receiving regular instruction worked in non-musical contexts.

\section{Instruments}

The instruments used measured both quantitative gains in academic performance and positive attitude, and qualitative reasons for those gains. The quantitative instruments used were a pretest, a posttest, a post-posttest, and a survey. The qualitative instrument used was semi-structured interviews. Details of each instrument are as follows:

\section{Pretest, Posttest, and Post-Posttest}

The pretest, posttest, and post-posttest were all of similar difficulty and each had four problems. Three problems in each test were adapted from the section quizzes in McDougal Littell's 2007 edition textbook Algebra I. The fourth problem in each test was 
adapted from the problem presented in the Get the Math in Music activity. Complete pretest, posttest, and post-posttest questions are provided in Appendix A.

The pretest, posttest, and post-posttest assessments were used to test my first hypothesis and answer my first research question. If the gains in subject knowledge between pretest and posttest were significantly greater for Group B than for Group A, then we might be able to attribute those gains to the implementation of the treatment. Additionally, if Group A showed greater gains from posttest to post-posttest than from pretest to posttest, that might also support the effectiveness of the treatment.

Some potential threats to internal validity are selection-history, selectionmaturation, and selection-testing (Trochim, 2006). A selection-history threat might be that some students of one group spent more time at home independently investigating ratio, proportion, and cross multiplication after the pretest than did the students in the other group. To guard against this threat, between pretest and posttest no homework involving ratio and proportion was assigned to either group. It is worth noting that the majority of students in both groups showed a great disdain for math. According to their teachers, few students ever did homework assignments.

A selection-maturation threat might be that despite the math faculty's best attempt at choosing two classes of equal academic performance, they could not predict which group of students would absorb the content more quickly. Similarly, a selection-testing threat could occur in that one group might learn more from the pretest than the other group. I moved forward, keeping in mind that selection-maturation and selection-testing threats were possible. All of the students in both groups had failed the previous semester 
of Geometry. At least by that broad standard, the groups were of equal academic performance.

Social interaction threats (Trochim, 2006) may also occur. One group might get word of the treatment, do a Google search for Get the Math in Music, and try the activity for themselves. A compensatory rivalry or resentful demoralization threat (Trochim, 2006) may also happen if Group A learns of the special activity that Group B is doing. To guard against these threats, Group A was given regular instruction and the posttest first, before Group B received the treatment. This way, all posttests used to compare the groups were completed and collected by me before any students had the opportunity to discuss the treatment outside of class.

A threat to the external validity may be that at this school, the sample of students available is not representative of the general high school population. These students might be exceptional learners and have a particular aptitude for math unlike other students at this school, or students at other schools. Alternatively, they may show less interest in math than other students at this school or students at other schools. This sample pool was not picked to be representative of the school or national average. Due to the limited scope of this study I realize that the generalizability of the results may be compromised. However, if the results of this study show that treatments like Get the Math in Music are effective for the students' learning and enjoyment within the scope of two classes at one school, then justification will exist to try the same study in a wide range of high schools with the hope that more generalizable conclusions can be found.

\section{Survey}


The survey contained questions similar to those in An et al. (2007). It consisted of eight questions regarding the student's interest in math and music, respectively. The answers were provided using a five point Likert scale. Response choices were: strongly agree, agree, neutral, disagree, and strongly disagree. The complete list of survey questions is provided in Appendix A.

A significant threat to the validity of the survey is apathy. Since it is a survey using a Likert scale, the student will most likely presume (correctly) that they will not receive a grade for their responses. In this case, it is possible that students won't be motivated to submit truthful answers. To guard against this I explained to students that the accuracy of their answers was important and beneficial to them because ultimately my study was concerned with making math more enjoyable for them. If it is true that most students in a remedial geometry class do not enjoy learning math, I anticipated their cooperation after telling them the goal of this study.

\section{Interviews}

Lastly, the semi-structured interviews I conducted posed several open-ended questions modeled after those used in Ben-Chaim, Keret, and Ilany (2007). Among the questions, the students were asked if they enjoyed the Get the Math in Music treatment more or less than the regular instruction. They were also asked to explain what they liked or did not like about the music activity. The complete list of interview questions is included in Appendix A. The interviews were conducted after both groups received the treatment and after all quantitative assessments were completed. 
At this stage in the study, after everyone had received the treatment, the distinctions between groups no longer existed and the interview questions were identical for all participating students. The primary purpose of the interview was to better understand why each student performed as they did. I wanted to learn in what way if any the Get the Math in Music activity helped or hindered their performance.

An important threat to validity to be concerned about in the interviews was a selection-instrumentation threat (Trochim, 2006). The students may say they liked the music activity just to please the interviewer. To mitigate this, at the outset of the interview, the importance of honesty in their responses was reiterated to the student being interviewed. The interviewer explained that cooperation and honesty are of the utmost importance, and that this study's ultimate goal was to make learning math more enjoyable for the student.

\section{Threats to Validity For All Instruments}

Construct validity (Trochim, 2006) is a major concern since the Get the Math in Music activity is delivered online in a format that might be more appealing to students than a textbook. If students learn the subject matter better after the treatment, it is possible that this is due to Get the Math in Music being an online tool, or to the activity giving audio feedback for wrong answers, or to the students disliking their textbook in particular. It would not be because of the construct I wish to test: the application of math in music. It is difficult to mitigate this threat. I theorized different ways to reduce this threat, but with each new solution, a new construct threat appeared. Ultimately the best way to deal with this threat is to find other math-music integration studies that benefited 
students to show that activities like Get the Math in Music are part of a bigger body of evidence illustrating the effectiveness of using music-related real world examples while teaching math.

\section{Procedure}

This study occurred over the course of several weeks at a high school in Northwest Oregon. It centered on one lesson reviewing ratio, proportion, cross multiplication. The lesson was taught by the same teacher (i.e., myself) to two preselected geometry classes considered to be evenly matched in academic performance by the math faculty at the school. Specifically, the students in these two groups had failed geometry in the preceding semester. These classes were to cover the same material in the same order as the preceding semester. One section served as Group A. The other served as Group B.

The groups did not receive geometry instruction on the same days. The school used an A/B schedule. Group A had class on A days while Group B had class on B days. I took this into account when deciding upon the sequence of events in this study in attempt to minimize social interaction threats.

Two weeks preceding the start of a unit on similarity, all students took the pretest. Then on the first day of the unit, Group A received normal instruction and took the posttest. The next day, Group B received the treatment, took the posttest, and completed the survey. One week later Group A received the treatment and completed the survey. Another week later, after I examined the results of the tests and surveys, a selection of students were given interviews. Interviewee selections were made to include students 
who improved, students who did the same, and students who did worse from one assessment to another.

The goal of the interviews was to add depth to the understanding of the results from the tests and survey. These interviews were conducted by me rather than by the teacher to minimize bias. The majority of interview questions were open-ended. For example, one question was: did you prefer the Get the Math in Music treatment to the regular class instruction and why? This question was given to allow the students to expand upon their answers. I documented the students' answers with notes containing paraphrase and quotes. The complete interview notes are included in Appendix C.

\section{Data Analysis}

Not all students returned signed consent forms. Of the 43 students who participated, 29 submitted signed consent forms. Therefore $N=29$. All test scores and survey responses were entered into an Excel spreadsheet. Paired sample $t$-tests of test scores were done in Minitab with the consultation of an expert. Survey response data mean, median, and mode values were calculated in Excel.

To answer the first research question (i.e., to what extent does the integration of Get the Math in Music improve students' academic performance in a remedial geometry review of ratio, proportion, and cross multiplication), a paired sample $t$-test was used to find out if Group B had statistically significantly greater gains from pretest to posttest than Group A. Another paired sample t-test was used to find out if Group A showed significant performance gains after receiving the treatment compared to when they received normal instruction. 
To answer the second research question (i.e., to what extent does participation in the Get the Math activity improve students' attitudes towards math), survey responses from all participating students were tallied to determine if a majority of students enjoyed math more after receiving the Get the Math in Music treatment. In particular the results of the fourth survey prompt (i.e., you like math more now that you have used it in an activity related to music, like Get the Math in Music) informed the answer to this question.

Lastly, the interview notes were evaluated in order to better understand the thinking of those students interviewed, and to determine if a majority of those students enjoyed math more after receiving the Get the Math in Music treatment. I first analyzed the responses to groups of questions based on what information those questions targeted. Then I made multiple passes over the notes looking for recurring themes and noting them with reference to supporting student responses. 


\section{Results}

\section{Research Question 1}

To what extent does the integration of Get the Math in Music improve students' academic performance in a remedial geometry review of ratio, proportion, and cross multiplication? To analyze this data I used a paired sample $t$-test of score gain by group. The test showed that greater improvement from pretest to posttest was correlated with being in Group B (P-Value=0.048). Group B received the treatment between pretest and posttest. On average this improvement was about 1 point. The following table shows these results:

\begin{tabular}{|c|c|c|c|c|c|}
\hline \multicolumn{6}{|c|}{$\begin{array}{l}\text { Table } 2 \\
\text { Comparison of pretest to posttest gains by group }\end{array}$} \\
\hline Group & $n$ & $M$ & $S D$ & $p$ & $95 \% \mathrm{CI}$ \\
\hline $\mathrm{A}$ & 17 & 0.41 & 1.06 & \multirow[t]{2}{*}{$0.048 *$} & \multirow[t]{2}{*}{$-1.835,-0.008$} \\
\hline B & 12 & 1.33 & 1.23 & & \\
\hline \multicolumn{6}{|c|}{$\begin{array}{l}\text { Note. A Two-Sample } t \text {-Test was used. } \mathrm{n}=\text { number of participants. } \mathrm{M}=\text { mean. } \mathrm{SD}=\text { standard } \\
\text { deviation. } \mathrm{CI}=\text { confidence interval. A total of } 4 \text { points was possible on each test. Consequently the } \\
\text { maximum gain or loss possible between tests was } 4 \text { points. } \\
* p<.05 \text { indicating a statistically significant difference between Group A and Group B gains at a } 95 \%\end{array}$} \\
\hline
\end{tabular}




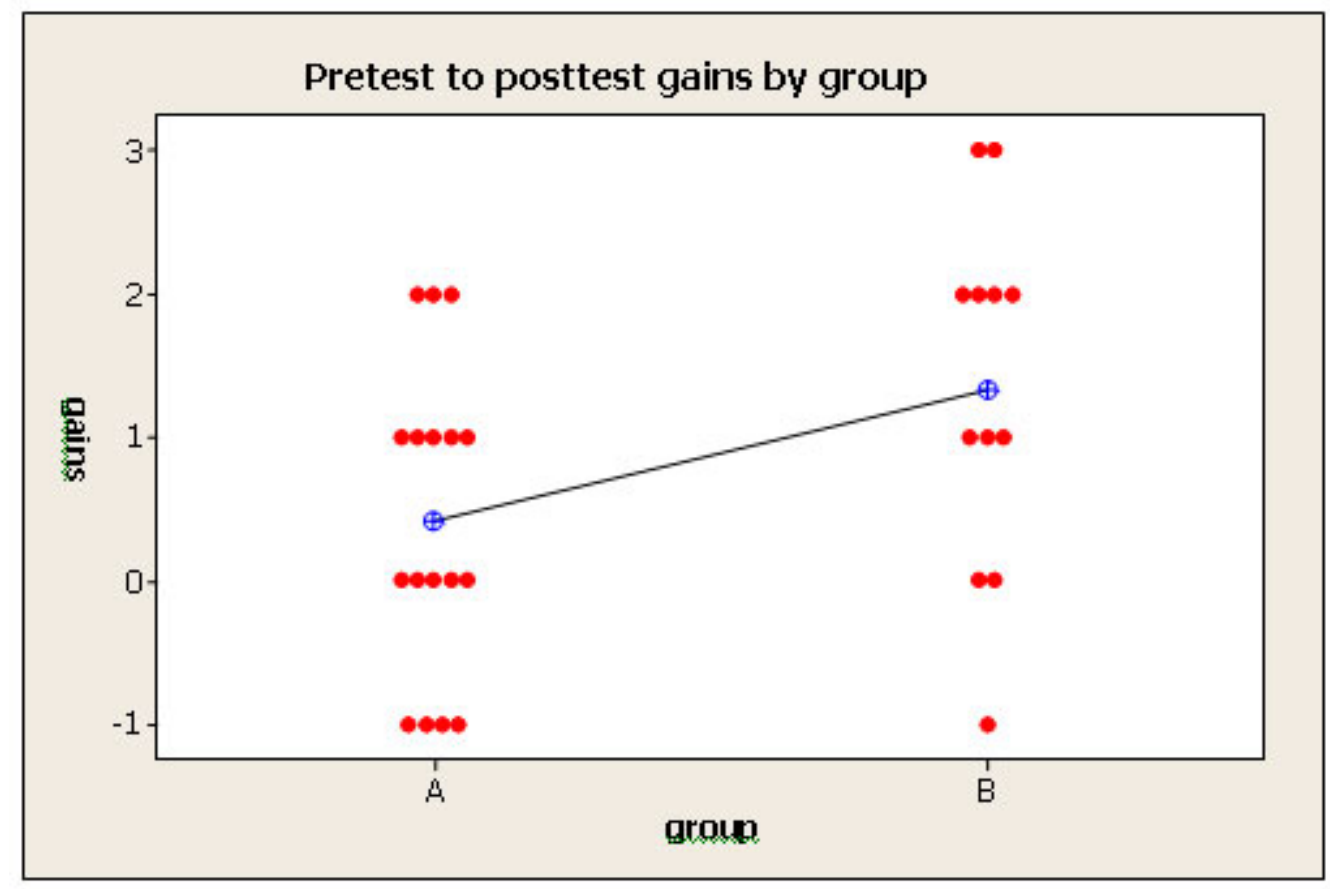

Figure 3. Pretest to posttest gains by group. This figure displays pretest to posttest gains for all participants. The line shows the increase in the mean gain from Group A to Group B $(p=0.048)$.

I also used a paired sample $t$-test to see if Group A showed larger gains between posttest and post-posttest (after they received the treatment) compared to between pretest and posttest. This test showed no significant difference in gains. The following table illustrates these results: 
Table 3

Comparison of pretest to posttest and posttest to post-posttest gains for Group A

\begin{tabular}{|l|c|c|c|c|c|}
\hline Tests & $n$ & $M$ & $S D$ & $p$ & $95 \%$ CI \\
\hline Pre to Post & 17 & 0.41 & 1.06 & \multirow{2}{*}{$\mathbf{0 . 8 7 0 *}$} & $-0.784,-0.666$ \\
\cline { 1 - 5 } Pre to post-post & 17 & .47 & 1.01 & & \\
\hline
\end{tabular}

Note. A Two-Sample $t$-Test was used. $\mathrm{n}=$ number of participants. $\mathrm{M}=$ mean. $\mathrm{SD}=$ standard

deviation. $\mathrm{CI}=$ confidence interval. A total of 4 points was possible on each test. Consequently the maximum gain or loss possible between tests was 4 points.

$* p>.05$ does not indicate a statistically significant difference between pretest to posttest and posttest to post-posttest gains at a $95 \%$ confidence level.

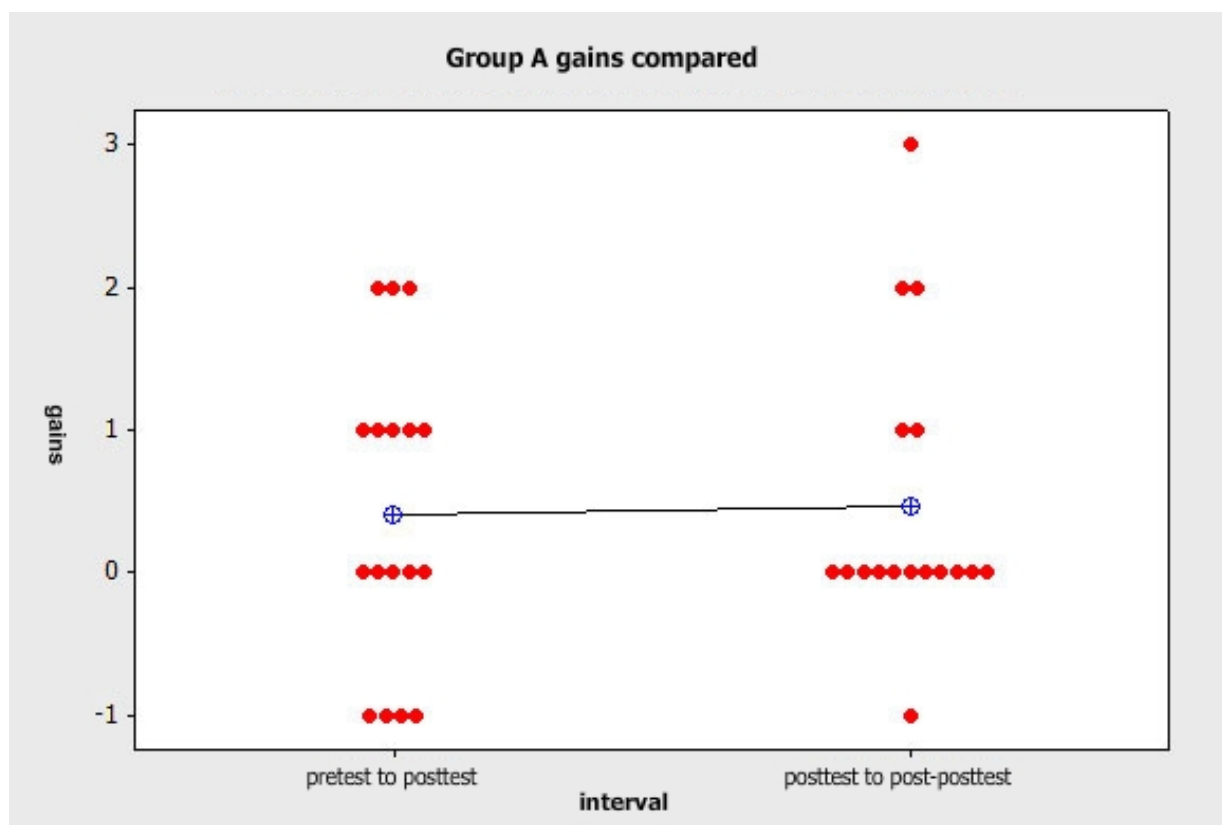

Figure 4. Pretest to posttest gains and posttest to post-posttest gains for Group A compared. This figure displays pretest to posttest gains compared to posttest to post-posttest gains for Group A. The line shows the increase in the mean gain from between pretest and posttest to between posttest and post-posttest $(p=$ $0.870)$. 
Note that most students in Group A showed no gain from posttest to post-posttest. A mean gain of 0.41 from pretest to posttest was very close to the mean gain of 0.47 from posttest to post-posttest for this group. Neither of these gain values were close to Group B's mean gain of 1.33 between pretest and posttest.

\section{Research Question 2}

To what extent does participation in the Get the Math activity improve students' attitudes towards math? I measured this with survey prompt number 4: you like math more now that you have used it in an activity related to music, like Get the Math in Music. The mean, median, and mode result for this prompt was a 2, indicating that most student were neutral in their response.

\section{Survey Prompt Averages}

On average, most students responded with neutral for survey questions 1 through 5. These questions all had to do with the student's appreciation of math. On average, most students responded with strongly agree, or agree, for questions 6 through 8 . These questions all had to do with the student's appreciation of music.

\section{Interviews}

Students interviewed were split on whether they preferred regular instruction over the Get the Math in Music activity. Of those interviewed, five students preferred the activity and four preferred regular instruction. Several of the students who preferred the activity said they like it because it was "different," and not necessarily because it involved music. 
Several students indicated their level of academic performance is primarily determined by their mood on any given day. For example student D said, "Sometimes I like it [math], sometimes I just don't want to do it." Student B said, "I probably didn't care that day for the first two tests." Student O said "I was being lazy for the first 2 tests."

Questions 1 and 2 of the interview sought to know if the student already had an affinity for math or music. Only one person, Student B, included music among an activity or topic that interests him on Question 1. For Question 2, only one person, Student S, said math was her favorite subject, but she specified not geometry.

Questions 3 and 4 sought to learn about the student's attitude and abilities with math. Only one person, Student D, said he enjoyed math (Question 3). Five people, Students B, G, O, X, and AA, said they did not enjoy math. Only one person, Student CC, said he was good at math while four students, Students B, G, W, and AA, said they were not.

Questions 5 and 6 sought to know about the student's attitude towards the treatment. In response to Question 5, six students (B, D, S, X, AA, CC) said they enjoyed the activity, one $(\mathrm{G})$ said it was alright, and two $(\mathrm{O}, \mathrm{W})$ did not care for it. Those interviewed were split five to four over whether they preferred the treatment to regular instruction. Five $(B, G, S, X, C C)$ said they preferred the treatment. Four (D, O, W, AA) preferred regular class. 
Question 7 was an open-ended self-evaluation. It sought to learn what students attributed their performance to. Responses revealed that several students interviewed admitted they may or may not try on any given day $(\mathrm{B}, \mathrm{O})$.

Question 8 was tied to the students' responses for survey questions 3 and 4 . It sought to find out how strongly the treatment improved the learning, if at all. Student D's response revealed that he may or may not try on any given day which is consistent to the results above for Question 7. Several students (D, G, S, AA) said they just did not like math. Several students $(\mathrm{G}, \mathrm{O}, \mathrm{W}, \mathrm{X})$ also said that for them the use of music to teach math was no big deal.

One recurring trend in the interview data is that students $(B, D, G, S)$ liked the treatment because it was "different", not because it was related to music. In fact, only one student (CC) said they liked the treatment specifically because it had to do with music. 


\section{Discussion}

Some evidence found in the data supports the hypothesis that using a musicrelated activity like Get the Math in Music is more effective than normal instruction in fostering better academic performance. The correlation $(p=0.048)$ of Group B with greater gains from pretest to posttest may indicate that the treatment was effective. On the other hand, no other data supports this. The treatment was not correlated $(p=0.870)$ with improving Group A's scores between posttest and post-posttest. This reason, along with the mixed reaction to the treatment as documented by the survey and interviews, makes it hard for me to feel confident that teaching with a music-related activity like Get the Math in Music is any more effective than normal instruction, even with adolescents, at improving academic performance in math.

Furthermore, the evidence does not support or refute the second hypothesis that students like math more after taking part in the Get the Math in Music activity. Survey question 4 specifically asked students if they liked math more as a result of taking part in the Get the Math in Music activity. The average response was neutral $(M \approx 2$ on a Likert scale where 2 indicates "neutral").

The average of a neutral response to the first five questions on the survey which measured student interest in math, along with interview data showing approximately half of those interviewed do not enjoy math, suggested that there was a widespread apathy among the students in these sections when it came to learning math. The activity alone did not change this apathy. Interviews showed that many students liked the activity, but 
not necessarily because it was related to music, and not enough to make them start liking math.

Survey questions 6-8 showed that music was important to most if not all students. These findings were consistent with those of North and Hargreaves (1999) regarding the nearly universal gravitation of adolescents towards music. On the survey, most students strongly agreed that they liked music and that they listened to it regularly. Ironically, in the nine interviews, only one student actually mentioned music as one of his interests.

The assertion in the literature that proportional reasoning is one of the most difficult concepts in math to teach and to learn (Lamon, 2007; Vasquez, Sneider, and Comer, 2013; Ben-Chaim, Keret, and Ilany, 2007) was also supported. The participants had all studied ratio and proportion several times before (i.e., in middle school, in Algebra 1, and in the first semester of Geometry) and yet the majority struggled on the pretest. The average pretest score was less than 50\%. Furthermore, even though all 4 problems on each test were of approximately the same level of difficulty, very few students got all four questions right on any of the tests.

One other conclusion that I was not expecting had to do with the importance of teacher-student relationships. Student W improved from 0 to 3 between pretest and posttest: a $75 \%$ improvement. By coincidence, this student had already been working with me during the entire school year in a class in another subject. When he took the pretest, Student $\mathrm{W}$ did not know that I was affiliated with it. On the day of the treatment I noticed that Student W seemed happy to see me serving as math teacher. I suspect that Student W's improvement between pretest and posttest scores was the result of our good 
academic relationship. This possibility is motivation for me to study teacher-student relationship building further. This experience made the importance of teacher-student relationships seem to be greater than that of novel activities.

In sum, teaching math to adolescents with music-related activities might still be an effective strategy. This research was not able to reliably conclude one way or another on that point. Further study on a larger scale and covering other mathematical topics would be helpful in determining if music-related activities pose some advantage to high school math students. Despite a lack of overwhelming evidence to support my initial hypotheses, this research still has some value. Several conclusions of this research support existing claims in the literature: adolescents love music and many people struggle with proportional reasoning. Also, from this experience I am reminded that relationships are as important as methodology in education - if not more. 


\section{References}

An, S.A., Ma, T., \& Capraro, M.M. (2007). Preservice teachers' beliefs and attitude about teaching and learning mathematics through music: An intervention study. School Science and Mathematics 111(5), 236-248.

Baggi, D.L. (2007). The need for alternative paradigms in science and engineering education. European Journal of Engineering Education 32(4), 441-449.

Ben-Chaim, D., Keret, Y., \& Ilany, B. (2007). Designing and implementing authentic investigative proportional reasoning tasks: The impact on pre-service mathematics teachers' content and pedagogical knowledge and attitudes. Journal of Mathematics Teacher Education 10, 333-340.

Carter, J., Cuevas, G., Day, R., \& Malloy, C. (2010). Geometry. Columbus, OH:Glencoe/McGraw-Hill.

Cohen, J.E. (1961). Some relationships between music and mathematics. Music Educators Journal 48, 104-109.

Courey, S.J., Balogh, E., Siker, J.R., \& Paik, J. (2012). Academic music: music instruction to engage third-grade students in learning basic fraction concepts. Educational Studies in Mathematics 81, 251-278.

Johnson, G.L. \& Edelson, R.J. (2003). Integrating music and mathematics in the elementary classroom. Teaching Children Mathematics 9(8), 474-479.

Lamon, S. (2007). Rational numbers and proportional reasoning: Toward a theoretical framework for research. In F. K. Lester (Ed.), Second handbook of research on 
mathematics teaching and learning (pp. 629-667). Charlotte, NC: Information Age Publishing.

Larson, R., Boswell, L., Kanold, T.D., \& Stiff, L. (2007). Algebra I. Evanston, IL:McDougal Littell.

National Governors Association Center for Best Practices, Council of Chief State School Officers. (2010). Common Core State Standards (Algebra). Washington D.C.: National Governors Association Center for Best Practices, Council of Chief State School Officers.

National Science Foundation. (n.d.) Math: What's the problem? Retrieved from http://www.nsf.gov/news/special_reports/math/textonly/index.jsp

North, A.C. \& Hargreaves, D.J. (1999). Music and adolescent identity. Music Education Research 1(1), 75-92.

Still, K., \& Bobis, J. (2005). The integration of mathematics and music in the primary school classroom. In P. Clarkson, A. Downton, D. Gronn, M. Horne, A. McDonough, R. Pierce \& A. Roche (Eds.). Proceedings of Annual Conference of the Mathematics Education Research Group of Australasia. Building Connections: Theory, Research and Practice (pp. 712-719). Melbourne: Deakin University Press.

Trochim, W.M. (2006). The Research Methods Knowledge Base ( $2^{\text {nd }}$ ed.). Retrieved from http://www.socialresearchmethods.net/kb/ 
Vasquez, J., Sneider, C., \& Comer, M. (2013). Stem Lesson Essentials, Grades 3-8: Integrating Science, Technology, Engineering, and Mathematics. Portsmouth, NH: Heinemann.

Wright, D. (2009). Mathematics and Music. Providence, RI: American Mathematical Society. 


\section{Appendix A: Instruments}

\section{Pretest}

Name

Date

Period

Assessment 1

Answer each question as best you can. Please show your work!

1) Holly baked 12 cookies with 4 ounces of raisins. Using the same ingredient ratio, how many cookies could she bake with one ounce of raisins?

2) Solve for $t$ and then check by substituting your solution into the original proportion.

$32 / t=24 / 3$

3) You just rode your bike for 50 minutes and burned 600 calories. How many calories did you burn per minute?

4) An audio sample of music has a duration of 9 seconds. You count 12 beats within that sample. How many beats per minute is the music? 


\section{Posttest}

Name

Date

Period

Assessment 2

Answer each question as best you can. Please show your work!

1) Polly baked 4 cakes with 12 eggs. Using the same ingredient ratio, how many cakes could she bake with 21 eggs?

2) Solve for $y$ and then check by substituting your solution into the original proportion.

$$
\frac{15}{3}=\frac{25}{y}
$$

3) You just ran for 30 minutes and burned 570 calories. How many calories did you burn per minute?

4) An audio sample of music has a duration of 8 seconds. You count 10 beats within that sample. How many beats per minute is the music? 


\section{Post-Posttest}

Name

Period
Date

Assessment 1

Answer each question as best you can. Please show your work!

1) Holly baked 20 cookies with 5 ounces of raisins. Using the same ingredient ratio, how many cookies could she bake with one ounce of raisins?

2) Solve for $t$ and then check by substituting your solution into the original proportion. $64 / t=24 / 3$

3) You just rode your bike for 60 minutes and burned 540 calories. How many calories did you burn per minute?

4) An audio sample of music has a duration of 12 seconds. You count 16 beats within that sample. How many beats per minute is the music? 


\section{Survey}

Name

Date

Period

Survey

Respond to each statement by circling A, B, C, D, or E accordingly.

1) You like math.
A. Strongly Agree
B. Agree
C. Neutral
D. Disagree
E. Strongly Disagree

2) Math is of more interest to you when it involves solving problems in the real world.
A. Strongly Agree
B. Agree
C. Neutral
D. Disagree
E. Strongly Disagree

3) You like math when it involves solving problems related to music, like in the Get the Math in Music activity.
A. Strongly Agree
B. Agree
C. Neutral
D. Disagree
E. Strongly Disagree

4) You like math more now that you have used it in an activity related to music, like Get the Math in Music.
A. Strongly Agree
B. Agree
C. Neutral
D. Disagree
E. Strongly Disagree

5) There are other uses of math in the real world, in activities besides music, which you would prefer to study.
A. Strongly Agree
B. Agree
C. Neutral
D. Disagree
E. Strongly Disagree

6) You like music.
A. Strongly Agree
B. Agree
C. Neutral
D. Disagree
E. Strongly Disagree

7) You play or listen to music regularly.
A. Strongly Agree
B. Agree
C. Neutral
D. Disagree
E. Strongly Disagree 
8) You consider music to be a big part of your life.
A. Strongly Agree
B. Agree
C. Neutral
D. Disagree
E. Strongly Disagree 


\section{Interview Questions}

Name

1) What sort of activities/topics interests you? For example, do you like nature, science, sports, fashion, cooking, etc.?

2) What is your favorite subject in school?

3) Do you enjoy math? What do you like or dislike about it?

4) Do you consider yourself good at math?

5) Did you enjoy the Get the Math in Music activity? Why?

6) Which did you prefer: the Get the Math in Music activity or regular in class instruction? Why?

7) Why do you think your test score improved between pre and post tests? (if it did)

8) Can you tell my about your answers to 3 and 4 on the survey? (look at surveys) 


\section{Appendix B: Complete Quantitative Data Set}

stu gr pre pos $g$ postp $g$ inter sur sur sur sur sur sur sur sur de ou tes ttes ai osttes ai vie vey vey vey vey vey vey vey vey

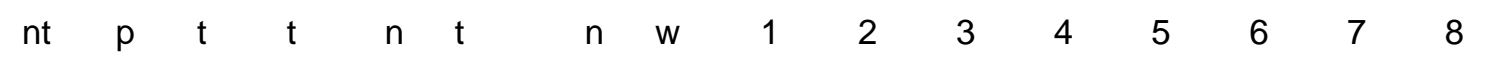
$\begin{array}{llllllllllllllll}\mathrm{A} & \mathrm{A} & 2 & 4 & 2 & 4 & 0 & 0 & 1 & 3 & 0 & 1 & 1 & 0 & 0 & 0\end{array}$ $\begin{array}{llllllllllllllll}\mathrm{B} & \mathrm{A} & 2 & 1 & -1 & 3 & 2 & 1 & 4 & 2 & 4 & 2 & 3 & 0 & 0 & 2\end{array}$ $\begin{array}{llllllllllllllll}\mathrm{C} & \mathrm{A} & 3 & 3 & 0 & 4 & 1 & 0 & 2 & 1 & 2 & 3 & 3 & 1 & 0 & 1\end{array}$ $\begin{array}{llllllllllllllll}\mathrm{D} & \mathrm{A} & 3 & 2 & -1 & 4 & 2 & 1 & 3 & 4 & 2 & 3 & 2 & 0 & 0 & 0\end{array}$ $\begin{array}{llllllllllllllll}\mathrm{E} & \mathrm{A} & 3 & 3 & 0 & 3 & 0 & 0 & 2 & 2 & 3 & 3 & 3 & 0 & 0 & 0\end{array}$ $\begin{array}{llllllllllllllll}\mathrm{F} & \mathrm{A} & 2 & 3 & 1 & 3 & 0 & 0 & 2 & 2 & 3 & 3 & 1 & 0 & 0 & 0\end{array}$ $\begin{array}{llllllllllllllll}\mathrm{G} & \mathrm{A} & 2 & 3 & 1 & 2 & -1 & 1 & 3 & 3 & 2 & 2 & 4 & 1 & 1 & 2\end{array}$ $\begin{array}{llllllllllllllll}\mathrm{H} & \mathrm{A} & 1 & 3 & 2 & 3 & 0 & 0 & 3 & 1 & 2 & 2 & 2 & 0 & 0 & 0\end{array}$ $\begin{array}{llllllllllllllll}\mathrm{I} & \mathrm{A} & 4 & 4 & 0 & 4 & 0 & 0 & 2 & 1 & 2 & 3 & 2 & 0 & 0 & 0\end{array}$ $\begin{array}{llllllllllllllll}\mathrm{J} & \mathrm{A} & 2 & 2 & 0 & 3 & 1 & 0 & 4 & 3 & 1 & 1 & 3 & 0 & 0 & 0\end{array}$ $\begin{array}{llllllllllllllll}\mathrm{K} & \mathrm{A} & 1 & 3 & 2 & 3 & 0 & 0 & 2 & 4 & 3 & 3 & 2 & 1 & 1 & 2\end{array}$ $\begin{array}{llllllllllllllll}\mathrm{L} & \mathrm{A} & 4 & 3 & -1 & 3 & 0 & 0 & 2 & 2 & 1 & 2 & 2 & 0 & 0 & 0\end{array}$ $\begin{array}{llllllllllllllll}M & \mathrm{~A} & 3 & 4 & 1 & 4 & 0 & 0 & 2 & 0 & 3 & 2 & 1 & 1 & 0 & 2\end{array}$ $\begin{array}{llllllllllllllll}\mathrm{N} & \mathrm{A} & 1 & 2 & 1 & 2 & 0 & 0 & 4 & 2 & 4 & 4 & 4 & 2 & 2 & 2\end{array}$ $\begin{array}{llllllllllllllll}\mathrm{O} & \mathrm{A} & 1 & 0 & -1 & 3 & 3 & 1 & 1 & 0 & 3 & 2 & 1 & 0 & 0 & 0\end{array}$ $\begin{array}{llllllllllllllll}\mathrm{P} & \mathrm{A} & 4 & 4 & 0 & 4 & 0 & 0 & 0 & 2 & 2 & 2 & 2 & 0 & 0 & 0\end{array}$ $\begin{array}{llllllllllllllll}\mathrm{Q} & \mathrm{A} & 2 & 3 & 1 & 3 & 0 & 0 & 3 & 0 & 1 & 2 & 1 & 0 & 0 & 0\end{array}$ $\begin{array}{llllllllllllllll}\mathrm{R} & \mathrm{B} & 2 & 3 & 1 & 0 & 0 & 0 & 2 & 1 & 3 & 1 & 3 & 0 & 0 & 0\end{array}$ $\begin{array}{llllllllllllllll}\mathrm{S} & \mathrm{B} & 3 & 2 & -1 & 0 & 0 & 1 & 2 & 2 & 1 & 1 & 1 & 1 & 1 & 1\end{array}$ $\begin{array}{llllllllllllllll}\mathrm{T} & \mathrm{B} & 0 & 2 & 2 & 0 & 0 & 0 & 4 & 1 & 3 & 3 & 2 & 0 & 0 & 0\end{array}$

$\begin{array}{llllllllllllllll}\mathrm{U} & \mathrm{B} & 3 & 4 & 1 & 0 & 0 & 0 & 1 & 1 & 2 & 2 & 2 & 0 & 0 & 1\end{array}$ $\begin{array}{llllllllllllllll}\mathrm{V} & \mathrm{B} & 0 & 2 & 2 & 0 & 0 & 0 & 3 & 2 & 3 & 2 & 2 & 0 & 0 & 0\end{array}$ 


$\begin{array}{llllllllllllllll}\text { W } & \text { B } & 0 & 3 & 3 & 0 & 0 & 1 & 3 & 4 & 2 & 3 & 2 & 0 & 0 & 1 \\ \mathrm{X} & \mathrm{B} & 2 & 4 & 2 & 0 & 0 & 1 & 2 & 1 & 1 & 2 & 1 & 1 & 1 & 1 \\ \mathrm{Y} & \mathrm{B} & 0 & 0 & 0 & 0 & 0 & 0 & 4 & 0 & 1 & 1 & 3 & 0 & 0 & 1 \\ \mathrm{Z} & \mathrm{B} & 1 & 2 & 1 & 0 & 0 & 0 & 2 & 2 & 1 & 2 & 1 & 0 & 0 & 0 \\ \mathrm{AA} & \mathrm{B} & 0 & 3 & 3 & 0 & 0 & 1 & 3 & 2 & 3 & 2 & 1 & 1 & 0 & 0 \\ \mathrm{BB} & \mathrm{B} & 1 & 3 & 2 & 0 & 0 & 0 & 3 & 3 & 2 & 2 & 2 & 0 & 0 & 0 \\ \mathrm{CC} & \mathrm{B} & 2 & 2 & 0 & 0 & 0 & 1 & 2 & 2 & 1 & 0 & 2 & 0 & 0 & 0\end{array}$




\section{Appendix C: Complete Interview Notes}

Name___ Student B

1) What sort of activities/topics interests you? For example, do you like nature, science, sports, fashion, cooking, etc.?

Basketball and music. That's about it.

2) What is your favorite subject in school?

Biology

3) Do you enjoy math? What do you like or dislike about it?

Not at all. I dislike everything about it. It is hard.

4) Do you consider yourself good at math?

No

5) Did you enjoy the Get the Math in Music activity? Why?

It was cool, because it was different.

6) Which did you prefer: the Get the Math in Music activity or regular in class instruction? Why? 
I preferred the activity, because it helped me learn better ways to solve different problems.

7) Why do you think your test score improved between pre and post tests? (if it did) I probably didn't care that day for the first two tests. The activity didn't introduce the concept, I already knew it.

8) Can you tell my about your answers to 3 and 4 on the survey? (look at surveys)

Re: 3. It's better than sitting in a classroom, getting bored by the teacher's voice. You can learn using something you like, like music. 
Name___ Student D

1) What sort of activities/topics interests you? For example, do you like nature, science, sports, fashion, cooking, etc.?

Sports, English, Drawing

2) What is your favorite subject in school?

P.E.

3) Do you enjoy math? What do you like or dislike about it?

Yes. It is challenging. Other times I just don't want to do it.

4) Do you consider yourself good at math?

I am ok.

5) Did you enjoy the Get the Math in Music activity? Why?

Yes, because of the different perspective on how to do math. Not necessarily because of the music.

6) Which did you prefer: the Get the Math in Music activity or regular in class instruction? Why? 
Regular class. Computer lab is all on the computer. If instruction was given in the lab it would be about the same.

7) Why do you think your test score improved between pre and post tests? (if it did)

On the computer it was easy it was easy to understand (how it was taught)

8) Can you tell my about your answers to 3 and 4 on the survey? (look at surveys)

Re: 4. I just don't like math that much. Sometimes I like it, sometimes I just don't want to do it. 
Name___ Student G

1) What sort of activities/topics interests you? For example, do you like nature, science, sports, fashion, cooking, etc.?

Cars

2) What is your favorite subject in school?

Wood, metals. Science.

3) Do you enjoy math? What do you like or dislike about it?

No. It is hard (harder than English or Science)

4) Do you consider yourself good at math?

No

5) Did you enjoy the Get the Math in Music activity? Why?

It was “alright." It was better than classroom instruction where it is easy to get distracted. It was something different.

6) Which did you prefer: the Get the Math in Music activity or regular in class instruction? Why?

Get the Math in Music. See \#5. 
7) Why do you think your test score improved between pre and post tests? (if it did) I saw these types of problems more than once. They made some sense already.

8) Can you tell my about your answers to 3 and 4 on the survey? (look at surveys)

Re: 3\&4: Teaching math with other things doesn't make a difference for me. 
Name____ Student O

1) What sort of activities/topics interests you? For example, do you like nature, science, sports, fashion, cooking, etc.?

Drawing is number one. Sports. I used to like math, but things got harder. I love science.

2) What is your favorite subject in school?

English.

3) Do you enjoy math? What do you like or dislike about it?

I used to. I used to be really good at it. I don't like story problems. I prefer numbers.

4) Do you consider yourself good at math?

I used to. Not now.

5) Did you enjoy the Get the Math in Music activity? Why?

I didn't understand it. What was the whole problem about?

6) Which did you prefer: the Get the Math in Music activity or regular in class instruction? Why?

Regular class instruction. I prefer the old fashioned way: the way I have always learned. It is easier. 
7) Why do you think your test score improved between pre and post tests? (if it did)

I was being lazy for the first 2 tests. (i.e., not the post posttest)

8) Can you tell my about your answers to 3 and 4 on the survey? (look at surveys)

Re: 4: This is my first time learning math with music. So I'm neutral because it was the first time. It might be better the second time. 
Name___ Student S

1) What sort of activities/topics interests you? For example, do you like nature, science, sports, fashion, cooking, etc.?

English, math (but not geometry), Martial Arts

2) What is your favorite subject in school?

math (but not geometry)

3) Do you enjoy math? What do you like or dislike about it?

It depends. I like algebra. It also depends on who is teaching.

4) Do you consider yourself good at math?

Algebra yes, geometry no.

5) Did you enjoy the Get the Math in Music activity? Why?

Yes. It was different. Not as procedural.

6) Which did you prefer: the Get the Math in Music activity or regular in class instruction? Why?

The activity. Because it is different.

7) Why do you think your test score improved between pre and post tests? (if it did) (her score stayed the same)

Review.

8) Can you tell my about your answers to 3 and 4 on the survey? (look at surveys) 
Every math class is the same (by textbook, by routine). Routine is the bad part of math teaching. 
Name Student W

1) What sort of activities/topics interests you? For example, do you like nature, science, sports, fashion, cooking, etc.?

Reading and Writing (fiction)

2) What is your favorite subject in school?

English, History (in general)

3) Do you enjoy math? What do you like or dislike about it?

When I understand it. Algebra more than geometry. It clicked easier. With algebra you just "plug it in" but with geometry "all pieces are strewn out" and you "need to make sense” of it.

4) Do you consider yourself good at math?

No. Larger class sizes make it harder to participate.

5) Did you enjoy the Get the Math in Music activity? Why?

Not too much. I'm into music, but not music production. I would rather be listening to music while working.

6) Which did you prefer: the Get the Math in Music activity or regular in class instruction? Why? 
I prefer regular textbook instruction because it is more generalized and can be applied to more things.

7) Why do you think your test score improved between pre and post tests? (if it did) The review lesson before the activity

8) Can you tell my about your answers to 3 and 4 on the survey? (look at surveys)

Re: 4. Not into music production 
Name___ Student X

1) What sort of activities/topics interests you? For example, do you like nature, science, sports, fashion, cooking, etc.?

Work on trucks. (We listen to music while doing it)

2) What is your favorite subject in school?

Physical Education

3) Do you enjoy math? What do you like or dislike about it?

It is ok, but not so much. I dislike big problems on paper. I am more into hands-on work, not pen and paper. I like doing problems in my head. It is easier for me than on paper.

4) Do you consider yourself good at math?

ok

5) Did you enjoy the Get the Math in Music activity? Why?

It was better than the textbook. The textbook is boring. There is nothing to it. Why? Everything is "slapped on a page." You read it and figure it out.

6) Which did you prefer: the Get the Math in Music activity or regular in class instruction? Why?

The activity.

7) Why do you think your test score improved between pre and post tests? (if it did) 
The Get the Math in Music activity. I could have been a different activity than music though (e.g., a mechanical activity)

8) Can you tell my about your answers to 3 and 4 on the survey? (look at surveys) re: 4, not necessarily. If it was about trucks I would have marked "agree.” 
Name Student AA

1) What sort of activities/topics interests you? For example, do you like nature, science, sports, fashion, cooking, etc.?

Gym, Shopping, Friends

2) What is your favorite subject in school?

English

3) Do you enjoy math? What do you like or dislike about it?

No. It is keeping me from graduating. It is hard.

4) Do you consider yourself good at math?

No

5) Did you enjoy the Get the Math in Music activity? Why?

Yes. Because it is related to real life. Real life examples are good in general, not necessarily musical ones.

6) Which did you prefer: the Get the Math in Music activity or regular in class instruction? Why?

I prefer regular textbook instruction if someone explains it well. I did not totally understand the activity. 
7) Why do you think your test score improved between pre and post tests? (if it did) Because I listened in class and the mini-lesson you gave (i.e., not the activity)

8) Can you tell my about your answers to 3 and 4 on the survey? (look at surveys)

Re: 3. I just don't like math. 
Name___ Student CC

1) What sort of activities/topics interests you? For example, do you like nature, science, sports, fashion, cooking, etc.?

Reading, Volleyball, time with family and friends

2) What is your favorite subject in school?

Global Studies

3) Do you enjoy math? What do you like or dislike about it?

Somewhat. Not when I don't get it.

4) Do you consider yourself good at math?

Yes.

5) Did you enjoy the Get the Math in Music activity? Why?

Yes. It was cool to relate math to music in general. I am familiar with music.

6) Which did you prefer: the Get the Math in Music activity or regular in class instruction? Why?

The activity: it is more interesting and not a lecture.

7) Why do you think your test score improved between pre and post tests? (if it did) I don't know, good question.

8) Can you tell my about your answers to 3 and 4 on the survey? (look at surveys) 
Re: 4. the example is better than the textbook. In music you learn other things than just the problem alone. 